\title{
Sloshing response of partially filled rectangular tank under periodic horizontal ground motion.
}

\author{
Amiya Pandit ${ }^{1+}$, and Kishore Chandra Biswal $^{2}$ \\ ${ }^{1,2}$ Department of Civil Engineering, NIT Rourkela, 769008, India
}

\begin{abstract}
The event caused due to the movement of the unrestricted free surface liquid in container due to any external excitation is known as sloshing. The problem of liquid sloshing phenomenon in stationary or in moving container is a great matter of concern for many researchers and engineers. The containers may range from a cup of milk, ponds, and lakes to fuel tanks of launching vehicles and cargo ships carrying variety of liquids such as oil, liquefied natural gas, and chemical fluids. As a result of sloshing there is spillage of liquid from the containers and it causes structural instability and structural damage. Due to these reasons, liquid retaining structures which are special in construction and in function from an engineering point of view must be constructed well to be resistant against oscillation of the liquid due to external excitations. The amount of liquid participating in the sloshing motion depends on the shape of tank, the liquid depth, internal objects, if any, orientation, duration, amplitude, and frequency contents of external excitations. This present study focuses on the forced vibration analysis of partially filled two-dimensional rigid rectangular tank numerically. A Finite element (FE) code in two dimensions is developed to understand the behavior of sloshing. This method is competent enough of evaluating both impulsive and convective response of tank-liquid system in terms of base shear and hydrodynamic pressure distribution along the walls of the containers.
\end{abstract}

\section{Introduction}

Sloshing of liquid in partly filled containers impose dynamic pressure along the walls of the containers, which results structural instability. So the study of sloshing in containers like fuel tanks running on the roads, cargo ships carrying chemicals or oil, fuel propellant of rockets and the overhead tanks containing liquids is a great matter of concern for different departments of engineering. In order to secure the containers in addition with the vicinity the complex behavior of sloshing should be analyzed precisely. The amplitude of slosh depends on some of the extensive parameters such as amplitude and frequency of excitation, shape and size of tank, liquid depth and liquid properties. Housner [1] performed analytical solution for both rectangular and cylindrical shape container considering a spring mass model to define the liquid sloshing. But it was highly objectionable as this concept was not fitting to arbitrary shape containers. So different mathematical models have been developed to investigate the dynamic response of liquid in containers. Aslam [2] approached finite element method to find out the sloshing displacement and hydrodynamic pressure in partially liquid filled annular tank and validated the numerical results with the experimental results which was in a good agreement.

\section{amiyaranjanpandit1991@gmail.com}

Veletsos et al. [3] numerically determined the response of circular cylindrical tank excited vertically, and calculated the hydrodynamic force at the base of the tank for flexible and rigid condition. Koh et al. [4] evaluated the dynamic response of three-dimensional rectangular liquid storage tanks, including free surface sloshing, subjected to horizontal ground excitation using the boundary element method. Faltinsen et al. [5] performed analytical analysis on 3-D tank at resonant condition and validated with the experimental results. Biswal et al. [6] evaluated the sloshing frequency in cylindrical tank without baffle and again applying both with flexible and rigid baffles. Finite element were used to discretize both liquid and structural domain. Arafa [7] formulated to study the sloshing behavior in partially filled rectangular tank without or with baffles placing at different position inside tank using finite element. The study exhibited, the baffles inside suppress the sloshing effect. A pressure based finite element method is employed by Mitra and Sinhamahapatra [8], to study the effect of submerged component on the sloshing effect on rectangular tank under earthquake excitation. Chen et al. [9] studied the nonlinear sloshing behavior in cylindrical and rectangular tank using the boundary element method and second order Taylor series expansion and compared with the experimental results obtained using a small scale model under horizontal harmonic and recorded earthquake 
excitation. Virrela et al. [10] computed and compared both linear wave theory and nonlinear wave theory using finite element package ABACUS and found that nonlinearity has no significance effect on the sloshing frequency. Nayak and Biswal [11-13] numerically conducted both linear and nonlinear analysis to evaluate the base shear, base moment and pressure distribution along the tank wall as well as the block wall, under seismic excitation.

A limited study has been carried out to distinguish between impulsive and convective component of liquid sloshing for rectangular study numerically. Present investigation gives an overall idea regarding these components under harmonic excitation with different frequency and amplitude of excitation.

\section{Mathematical Formulations}

Figure 1 shows the problem geometry for rectangular tank, showing the Cartesian coordinate system $\mathrm{o}-\mathrm{xz}$, where origin is at the midpoint of the free surface with $\mathrm{z}$ axis pointing vertically upward and $\mathrm{x}$ axis along the direction of length (L) of the tank. The liquid is considered to be inviscid, incompressible and flow is assumed to be irrotational. For the linear analysis wave breaking is not considered. The governing equation for motion of liquid in terms of velocity potential, $\phi(\mathrm{x}, \mathrm{z}, \mathrm{t})$ is thus expressed by Laplace equation:

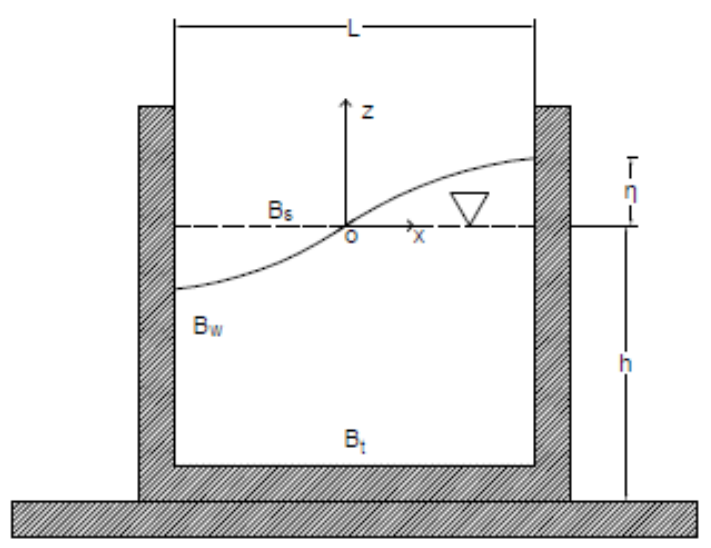

Fig. 1. Schematic diagram of rectangular tank.

$$
\nabla^{2} \varnothing=0
$$

At the free surface, combination of kinematic and dynamic boundary condition gives rise to

$$
\frac{\partial^{2} \emptyset}{\partial t^{2}}+\boldsymbol{g} \frac{\partial^{2} \emptyset}{\partial t^{2}}=0 \quad \text { on } \mathrm{B}_{\mathrm{s}}
$$

$\frac{\partial \emptyset}{\partial n}=\boldsymbol{V}_{n} \quad$ along the side walls of the container

$\frac{\partial \emptyset}{\partial n}=0$ at the bottom of the tank

where $\mathbf{V}_{\mathbf{n}}$ is the velocity normal to the walls of the container.

\section{Finite element formulation of liquid domain}

The liquid domain $\Omega$ bounded by $B=B_{t} \cup B_{s} \cup B_{w}$ is discretized by four nodded iso-parametric quadrilateral element as shown in Figure 2, and velocity potential is considered as the degree freedom. The velocity potential is approximated as

$$
\emptyset \approx \emptyset(x, z, t)=\sum_{j=1}^{n} \emptyset_{j} N_{j}(x, z)
$$

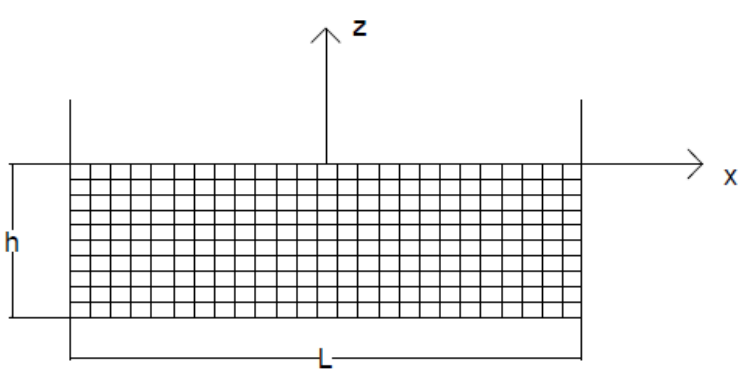

Fig. 2. Typical finite element mesh for fluid domain

Where $\phi_{\mathrm{j}}$ are time dependent nodal velocity potentials, $\mathrm{N}_{\mathrm{j}}$ are the shape functions and $\mathrm{n}$ is the number of nodes. Application of Galerkin's weighted residual method to Laplace equation gives rise to

$$
\int_{B} N_{i}\left[\frac{\partial^{2} \emptyset}{\partial x^{2}}+\frac{\partial^{2} \emptyset}{\partial z^{2}}\right] d B=0
$$

On application of product rule and after rearrangements

we

$\int_{B}\left(\frac{\partial N_{i}}{\partial x} \sum_{j=1}^{n} \frac{\partial N_{j}}{\partial x}+\frac{\partial N_{j}}{\partial z} \sum_{j=1}^{n} \frac{\partial N_{j}}{\partial z}\right) \emptyset_{j} d B-\int_{B} \frac{\partial}{\partial x}\left(N_{i} \frac{\partial \emptyset}{\partial x}\right)+$ $\frac{\partial}{\partial z}\left(N_{i} \frac{\partial \emptyset}{\partial z}\right) d B$ 
Applying the boundary conditions in equation (7)

$\frac{1}{g} \int_{T_{f s}} N_{i} \sum_{j=1}^{n} N_{j} \ddot{\varnothing} d T_{f S}+$

$$
\begin{array}{ll}
{\left[\int_{B} \frac{\partial N_{i}}{\partial x} \sum_{j=1}^{n} \frac{\partial N_{j}}{\partial x}+\right.} & \left.\frac{\partial N_{i}}{\partial z} \sum_{j=1}^{n} \frac{\partial N_{j}}{\partial x}\right] \emptyset_{j} d B= \\
\int_{T_{s w}} N_{i} \boldsymbol{V}_{n} d T_{S w} &
\end{array}
$$$$
\left[M_{f}\right]\{\ddot{\varnothing}\}+[K]\{\varnothing\}=\{F\}
$$

where $\left[M_{f}\right]$ is the free surface matrix

$\left[K_{f}\right]$ is the fluid coefficient matrix

$\left\{F_{i}\right\}$ is the force vector

$$
\begin{gathered}
M_{i j}=\frac{1}{g} \int_{T_{f s}} N_{i} N_{j} d T_{f s} \\
K_{i j}=\int_{B}\left(\frac{\partial N_{i}}{\partial x} \frac{\partial N_{j}}{\partial x}+\frac{\partial N_{i}}{\partial z} \frac{\partial N_{i}}{\partial z}\right) d B \\
F_{i}=-\int_{T_{s w}} N_{i} V_{n} d T_{s w}
\end{gathered}
$$

The hydrodynamic pressure $p$ and slosh amplitude $\eta$ at any instant are obtained from given equation

$$
\begin{gathered}
p=-\rho \frac{\partial \emptyset}{\partial t} \\
\eta=-\frac{1}{g} \frac{\partial \emptyset}{\partial t}
\end{gathered}
$$

The base shear $\mathrm{S}_{\mathrm{b}}$ can be evaluated using

$$
S_{b}=\int_{T_{s w}} p n_{x} d T_{s w}
$$

where, $n_{x}$ is the unit normal vector.

\section{Results and discussion}

A finite element code in MATLAB has been developed to evaluate the sloshing frequency, free slosh displacements, hydrodynamic pressure on tank wall and base shear for partially filled rectangular tank under horizontal excitation. The density of liquid $=1000 \mathrm{~kg} / \mathrm{m}^{3}$

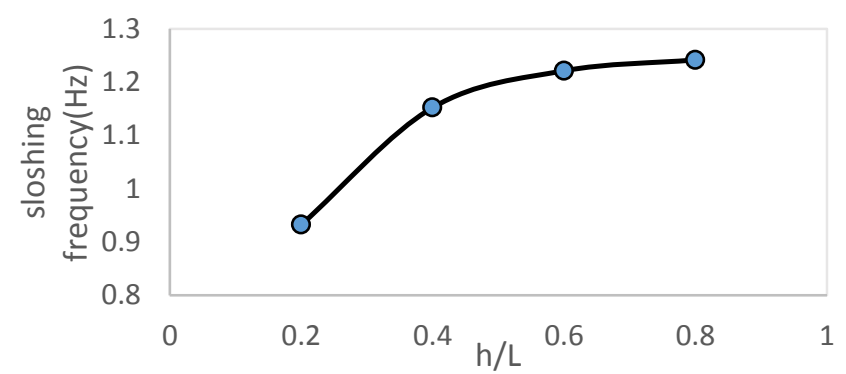

Fig. 3. Variation sloshing frequency

Figure 3 shows as the depth of liquid increases sloshing frequency increases initially and becomes less significant later on. The tank of length (L) $0.6 \mathrm{~m}$, liquid depth $0.08 \mathrm{~m}$ and width is kept unity for this present study. The natural sloshing frequency is found to be $0.7181 \mathrm{~Hz}$. The amplitude of excitation (a) is kept $5 \mathrm{~mm}$ and the harmonic ground motion applied to the tank is given be $\mathrm{y}=\mathrm{a} \sin \omega_{1} \mathrm{t}+\mathrm{a} \sin \omega_{2} \mathrm{t}$

where $\omega_{1}, \omega_{2}=$ excitation frequency in $\mathrm{rad} / \mathrm{sec}$. The excitation frequency is 0.8 times of natural sloshing frequency so that linearization assumption can be maintained appropriately.

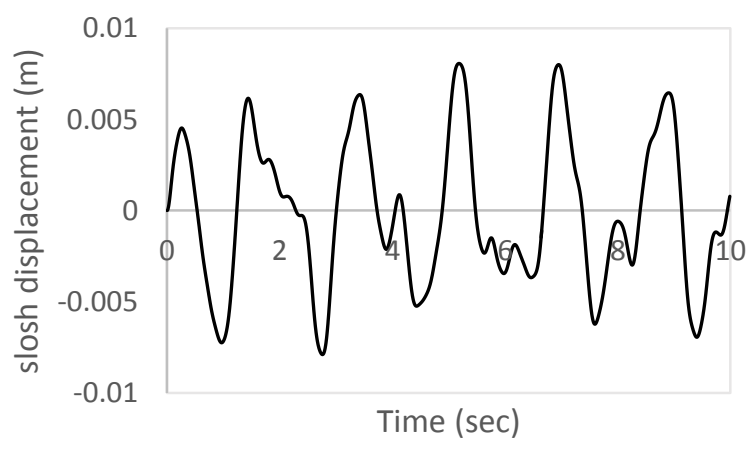

Fig.4. Time history of slosh displacement

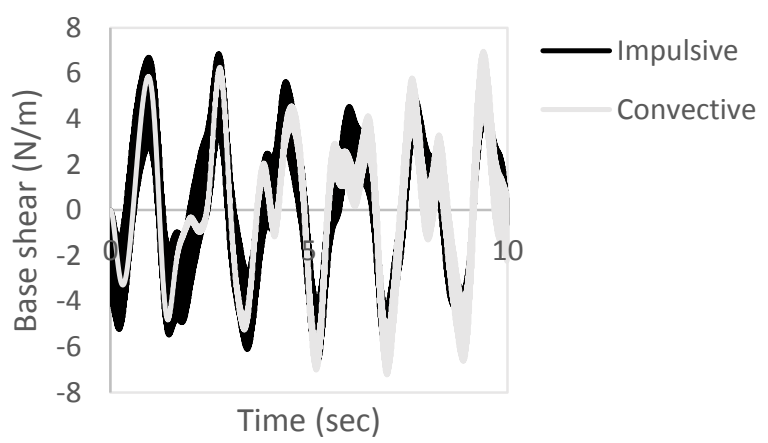

Fig. 5. Time history of base shear 


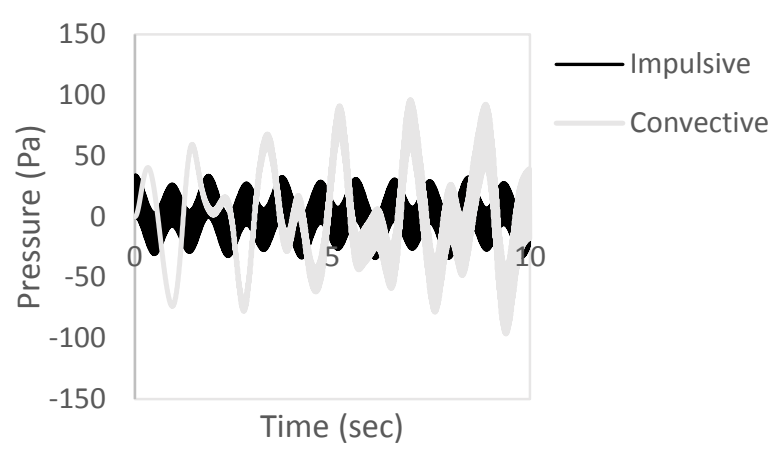

Fig. 6. Time history of pressure

The amount of liquid effectively participates in sloshing is termed as convective component of contained liquid and rest is termed as impulsive component of contained liquid.

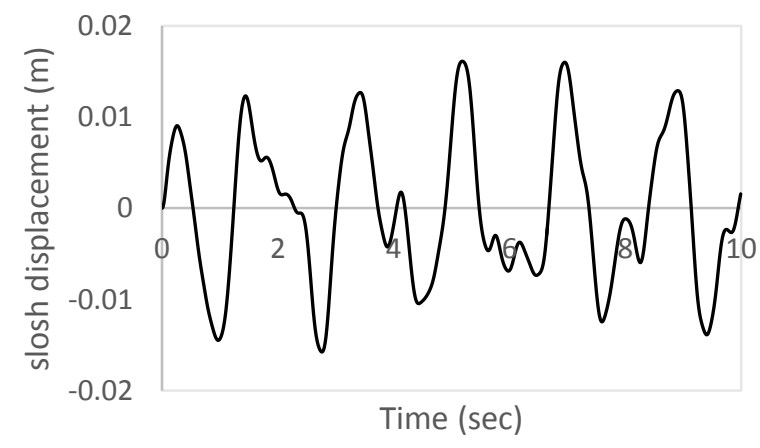

Fig. 7. Time history of slosh displacement

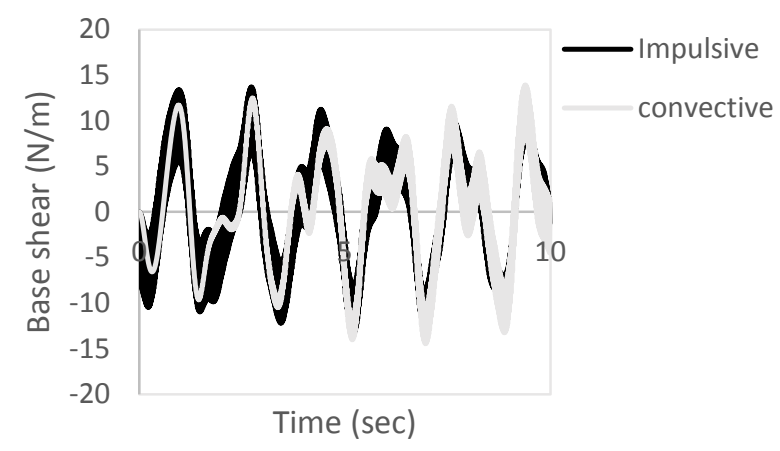

Fig. 8. Time history of base shear

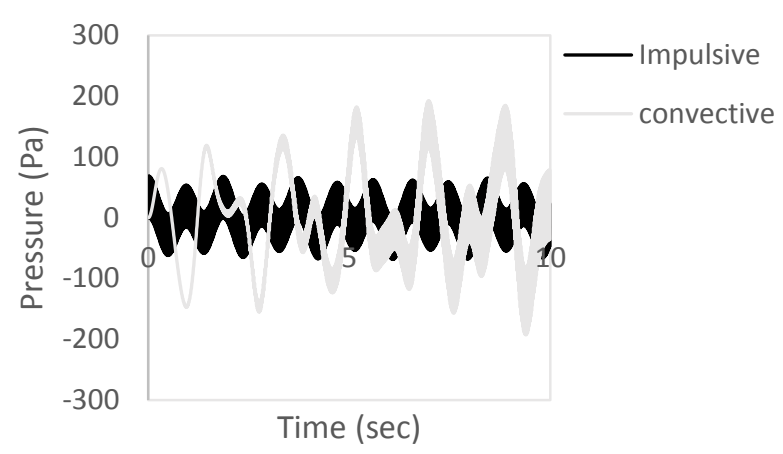

Fig. 9. Time history of pressure

Figure 4 and 6 shows the time history of slosh displacement from the free surface of liquid on left wall at different amplitude of excitation i.e. $5 \mathrm{~mm}$ and $10 \mathrm{~mm}$. As it can be clearly visible as the amplitude of excitation increases the slosh displacement increases considerably. Same behavior can be marked out for base shear generated and pressure acting on the left walls of the containers. From figure 5 and 8 it is visible that when excitation starts the convective component is less activated but as period of excitation has increased, the convective component of liquid starts to participates in sloshing more actively. As the amplitude of excitation has increased the response of base shear and pressure have also increased.

Since the accurate calculation of base shear and pressure induced due to sloshing is necessary in order avoid failure of tank liquid system. Again to achieve more accuracy the classification between impulsive and convective component is carried out numerically in the present analysis.

\section{Conclusion}

The numerical model effectively predicts the slosh displacement, base shear and pressure induced due to liquid sloshing in 2D rectangular container. The result shown in the present study, compares for same mass of liquid and without changing any dimension of the rectangular tank under harmonic excitation with amplitude of excitation $5 \mathrm{~mm}$ and $10 \mathrm{~mm}$ respectively. Higher value for amplitude of excitation enhance the participation of liquid in container as a consequence of which the dynamic response also increased. The importance of the present investigation can be analyzed by virtue of the classification between the impulsive and convective component of liquid sloshing. 


\section{References}

1. G.W. Housner, Bull. Seis. Soc. America, 53, 2 (1963).

2. M. Aslam, Int. J. Num. Meth. Eng, 17, 159-170 (1981).

3. A.S. Veletsos, J. Str. Eng., 112, 6 (1986).

4. C.G. Koh, S. Mahatma, C.M. Wang, J. Eartquake. Eng. Str. Dyn, 23, 17-31 (1994).

5. O. $M$ Faltinsen, O.V. Rognebakke, A.N. Timokha, J. Fluid. Dyn., 487, (2003).

6. K.C. Biswal, S. K. Bhattacharya, P. K. Sinha, J. Sou. Vib., 259, 177-192 (2003).

7. M. Arafa, J. Vib. Cont., 13, 7 (2007).

8. S. Mitra, K.P. Sinhamahaptra., J. Sou. Vib., 304, 361-381 (2007).

9. Y. H. Chen, W. Whang, C. Koh, Eatq. Eng, Str. Dyn., 36, 1701-1717 (2007).

10. J. C. Virella, O.V. Prato, C. A. Godoy, J. Sou. Vib., 312, 442-460 (2008).

11. S. K. Nayak, K.C. Biswal, J. Eatq. Eng., 17, 1023-1062 (2013).

12. S. K. Nayak, K.C. Biswal, Str. Eng. Meca., 47, 5 (2013).

13. S.K. Nayak, K.C. Biswal, J. Sou. Vib., 368, 148173 (2016). 